\title{
The Development of a Tool to Monitor the Impact of Flexible Conditions, Including Remote Employment, on Youth Work-Life Balance Parameters
}

\author{
Natalia Tonkikh, Tatiana Markova*, and Elena Zaborova \\ Ural State University of Economics, 620144 Ekaterinburg, Russia
}

\begin{abstract}
Transformational processes in labor relations affect the employees' social well-being. The published empirical works show that the values and perceptions of employment conditions differ among employees of various generations. The authors set the goal to develop and test a tool to monitor the work-life balance parameters of young people, belonging to the economically active part of Generation $\mathrm{Z}$. The tool should be able to identify real and desired models of work-life balance and monitor wellbeing by satisfaction with the established ratio in the distribution of personal time over key areas that characterize the quality of life depending on the form and type of labor relations. When developing the tool, the authors paid special attention to the possibility of measuring the impact of modern flexible employment formats, including remote employment, on the social well-being of working youth of generation $\mathrm{Z}$. The authors rely on the provisions of work/family border theory, generational theories and methods for assessing workplace toxicity. The application of sociological methods and instruments is justified. The authors developed a questionnaire for monitoring the satisfaction rate, tested during the pilot expert survey of young specialists in the Russian labor market by running a personal formalized survey. The respondents' responses were recorded in Google online questionnaire. An expert survey was conducted in May 2020. The results obtained confirmed that the tool allows to assess the required parameters. There was identified a positive relationship between flexible forms of employment and satisfaction with the work-life balance in the youth environment. Further research is considered to be promising.
\end{abstract}

\section{Introduction}

The problems of work-life balance have been actively studied since the $70 \mathrm{~s}$ - early $80 \mathrm{~s}$ of the last century, but the greatest interest has been manifested in recent decades. Researchers note there is a high proportion of the population that is not satisfied with the established ratio of time spent on paid employment and other areas of life. Under the influence of digitalization, employment conditions and labor relations are actively transforming, which cannot but affect the average "portrait" of work-life balance. We have

\footnotetext{
*Corresponding author: tmark@mail.ru
} 
both positive and negative consequences. On the one hand, the use of information and communication technologies (ICT) encourages the further spread of flexible, remote employment, which is quite attractive and convenient for many employees. Flexible employment, including remote employment, provides the opportunity for additional earnings and the ability to manage the schedule and place of work [1]. On the other hand, remote employment contributes to the "blurring" of work-life boundaries [2]. Online availability of an employee $24 / 7$ is perceived by employers as a sign of the highest degree of work involvement, but life in such a rhythm can lead to weakening of the nervous system, professional burnout, depression and other negative consequences. In terms of workers, such employment can be attributed to toxic jobs $[3,4,5]$.

Against the background of labor relations digitalization, processes are underway to replace one generation of workers with another, and in the near future most of the human resources will be represented by young specialists aged 18-35. The new generation has specific values. They are identified and continue to be clarified in the theory of generations $\mathrm{X}, \mathrm{Y}$ and $\mathrm{Z}[6,7]$, and should be taken into account when forming personnel strategies at macro, meso- and micro-levels. As a rule, employees of this age group have the following qualities: flexibility, mobility, high degree of learning ability and ambition. Modern young people often adhere to the philosophy of a healthy lifestyle, continuous self-development. The desire to achieve an optimal work-life balance is one of the key needs of younger people in our time. If for generation $\mathrm{X}$ and the first half of generation $\mathrm{Y}$ work ranks first in the list of priorities, then workers born in the late 90 s and early 2000 s increasingly rank personal life first. The topic of work-life balance for this category of the population is especially relevant.

Let us note that the issues of work-life balance are often studied in a generalized sense, without age segmentation. The authors have the following discussion hypothesis: flexible employment formants, including remote employment, can be a mechanism that allows to balance time commitment to personal life and work. The basis for the hypothesis is the specificity of flexible employment conditions, which implies the lack of a fixed place of work, independent planning of working hours, the possibility of vertical and horizontal professional movement within a short period, a change in functions and roles to avoid burnout and overwork.

\section{Statement of the Scientific Task and Methodology of Pilot Research}

The purpose of the present study is to develop and test a methodological tool that allows: to monitor, assess the reality and preferences in the distribution of personal time resources among young people in key areas that characterize quality of life; identify the existence or absence of a correlation between forms of employment and satisfaction with work-life balance.

To achieve this goal, the following objectives are set:

1. Clarify the constituent elements of the life balance wheel based on the theoretical systematization of scientific approaches to the study of the problem of work-life balance.

2. Develop a methodological approach and tool to assess the current and desired worklife balance of young people.

3. Test the methodology via pilot sociological research, identify the presence/absence of the influence of flexible forms of employment, including remote ones, on satisfaction with the work-life balance.

The object of the study is the adult and economically active part of generation $\mathrm{Z}$, the authors also studied the values and opinions of young people aged 18-25. The subject of the study is the actual (real) and desired (expected) "work-life balance". In the process of 
developing the toolkit, the authors relied on a methodological approach describing 5 "worklife balance" models on the basis of the studies conducted by Zedeck, Mosier and O’Driscoll $[8,9,10]$.

1. Segmentation model - independence of spheres, lack of influence.

2. The side effect model - the presence of the influence of one sphere on another in a positive or negative way.

3. Compensatory model - a person lacking satisfaction with one sphere can get the necessary satisfaction in another sphere.

4. Instrumental model - one area contributes to the success in another area.

5. Conflict model - the inevitability of conflicts and complex solutions if there is a high level of requirements in all spheres of life.

The authors developed a questionnaire containing 17 questions of a predominantly close-end type. Respondents are requested: to tick the options they agree with; prioritize options; assess the current and desired work-life balance. An open-end question is designed to identify young people's understanding of the term "work-life balance". The authors' tool for assessing the work-life balance identifies the following areas: family and children (relations with relatives); work, career; hobbies, personal time, rest; relationship with spouse/partner; relations and communication with friends; sport, physical activity, health; training, development. A wheel of life balance is supposed to be built on a broader grouping: work, family, hobby, health, education, and training. Respondents can rate the current state of work-life balance on a scale from 0 to 10 , where " 0 - spend all the time on personal life, 5 - work-life balance; and 10 - I devote to work all the time". Current estimates can be correlated with the desired condition that seem to be ideal for respondents.

The tool was tested by conducting a pilot expert survey. The survey was launched in early May 2020 and involved 30 respondents. Experts were selected by the snowball method. Pilot research technology: a formalized personal survey, the questionnaire was completed by an interviewer in a Google form. Interviewers also monitored the adequacy of respondents' understanding of the questions' wording.

At the time of the survey, the bulk of respondents was employed, $20.0 \%$ were in search of work. The structure of employment of working experts is as follows: $26.1 \%$ - services; $21.7 \%$ - marketing; $17.0 \%$ - logistics and procurement; retail trade and sales amounted to $13.0 \%$ each (here are indicated the predominant areas, although among surveyed experts there were those engaged in other economic activities).

The results showed that at the time of the survey, most of the experts focused more on work-related things than personal issues (57.3\%); less than a quarter of respondents noted they had a perfect work-life balance (they chose the average mark of 5 points); for $15.2 \%$ of experts, personal life appeared to be more important. It was revealed that quite often the real time distribution over different spheres of life does not coincide with the desired time patterns. So, most experts $(60.6 \%)$ would like to strike a balance between personal life and work-related commitments. About one in four would like to devote more time to personal life than to work. However, $15 \%$ of respondents are ready to give preference to work, career, with less attention to personal life.

\section{Conclusion}

The testing of the authors' instrument confirmed its quality, the possibility of its application for monitoring purposes, and the opportunity to identify, describe, and typify work-life balance models among the youth. The authors tend to think that the tool will allow to obtain interesting findings not only from a scientific, but also from a practical perspective. Identifying the needs and expectations of the future employee regarding the observance of the boundaries of their work-life balance is of high relevance at the stage of personnel 
selection, and enables the human resources staff to choose an adequate compensation model for work intensity.

According to the findings of the pilot study into values of the younger generation of employees aged 18-25, it was revealed that young people have a high degree of willingness to "sacrifice" their personal life, provided they are offered sufficient material compensation (61.8\%). For every second expert, work on an interesting project is important, when achieving success, a sense of satisfaction is achieved, for the sake of which young people are ready to periodically work long hours. Every fourth is ready to sacrifice their personal life in case they are offered compensation in the form of an additional weekend or comfortable working conditions (an office with a cafe, a swimming pool, a gym).The latter will allow the employee to allocate time for oneself, relax, being near the office, and without wasting time on the way to the gym or pool. It should be noted that $11.8 \%$ of experts are not ready to infringe their privacy in favor of work, even with material and/or intangible compensation for overtime work.

The results of the study confirmed the relationship between forms of employment and satisfaction with the work-life balance. The youth showed the greatest interest in flexible working hours with a flexible start and end of the working day (47.1\%). Due to this format, it becomes possible to plan a working day, have time to handle not only work-related commitments, but also devote more time to personal life (55.9\% of respondents believe), and there is time left for education, hobbies, self-development and other non-work activities $(29.4 \%)$. Less than a quarter believe that flexible working hours will not affect their lives in any way $(17.6 \%)$, only $8.8 \%$ noted negative consequences. It should be pointed out that the data obtained differ dramatically from the results of the regional study on the problems of non-standard employment, which was conducted by N. V. Tonkikh and T. A. Kamarova in 2015 in the Sverdlovsk region (the survey covered more than 1,500 people, the main share of the sample was represented by the population aged 25 to 45 years). More than $65.0 \%$ of respondents were interested in standard workplaces on the employer's premises with regular working hours. This fact shows a significant shift in the system of the younger generation's values regarding employment conditions.

An expert survey of the youth showed that every third of the respondents would prefer a combined form of labor organization: a combination of remote (distance) and office-based work $(38.2 \%)$. It should also be stated that in a group of experts who, according to their own estimates, are in a state of balance between personal life and work, the majority prefer flexible working hours; $17.2 \%$ chose a completely remote work format or shift-based schedule $(2 / 2$, etc.); The standard 8 -hour working week suits only $29.4 \%$ respondents.

Thus, there is a positive relationship between flexible forms of employment and satisfaction with the work-life balance in the youth environment. We consider that further research into this issue appears to be very promising.

\section{Acknowledgements}

The research was carried out with the support of the Russian Foundation for Basic Research in the framework of the scientific project No. 19-010-00705 "Development of tools for assessing the impact of social pollution of labor relations on the workers' wellbeing in the digital economy".

\section{References}

1. E. K. Dimitrova, N. V. Tonkikh, Human Progress, 6 (2020)

2. E. Koekemoer, S. Afr. J. Econ. Manag. Sci., 19(2) (2016)

3. K. Lawrence, UNC Exec. Dev., 1 (2014) 
4. J. Pfeffer, Acad. Manag. Perspect., 24 (2010)

5. A. Fedorova, Z. Dvorakova et al., Eur. Proc. Soc. Behav. Sci., 37 (2018)

6. B. Chillakuri, J. Org. Change Manag., 2 (2020)

7. J. Kutlak, Proc. Bus. \& Manag. Conf., 7 (2018)

8. S. Zedeck, K. L. Mosier, American psychologist, 45 (1990)

9. P. Allis, M. O’Driscoll, J. Manag. Psychol., 23 (2008)

10. S. T. Akinyele, M. C. Peters, F. E. Akinyele, Int. J. Manag. Stud. Res., 4 (2016) 